\title{
Simplified quantification of PET myocardial blood flow: The need for technical standardization
}

\author{
Jonathan B. Moody, PhD, ${ }^{\mathrm{a}}$ Edward P. Ficaro, PhD, ${ }^{\mathrm{a}, \mathrm{b}, \mathrm{d}}$ and Venkatesh L. Murthy, \\ $\mathrm{MD}, \mathrm{PhD}^{\mathrm{b}, \mathrm{c}, \mathrm{d}}$ \\ a INVIA Medical Imaging Solutions, Ann Arbor, MI \\ b Cardiac Imaging Program, University of Michigan, Ann Arbor, MI \\ c Division of Cardiovascular Medicine, Department of Internal Medicine, University of Michigan, \\ Ann Arbor, MI \\ d Division of Nuclear Medicine, Department of Radiology, University of Michigan, Ann Arbor, MI
}

Received Oct 11, 2018; accepted Oct 12, 2018

doi: $10.1007 / \mathrm{s} 12350-018-01497-8$

\section{See related article, pp. 819-828}

Noninvasive estimation of absolute myocardial blood flow (MBF) by positron emission tomography (PET) has a long history in clinical imaging. ${ }^{1-3}$ Many different flow models have been developed over the years, ${ }^{4-10}$ which have prompted numerous model comparison studies. ${ }^{11-13}$ In recent years, several of these validated flow models have now been implemented in a new generation of software applications. ${ }^{14-18}$ Thus, the focus has gradually shifted from development and validation of flow models to implementation and wider dissemination of clinical tools for MBF estimation in routine patient care. This new focus has emphasized the pressing need for technical standardization.

In this issue, the study of Chang et al ${ }^{19}$ continues this trend. The authors compared ${ }^{13} \mathrm{~N}$-ammonia MBF quantification using two previously validated $\mathrm{MBF}$ models provided by two FDA-approved commercial software packages: the simplified retention model $^{8}$ implemented in HeartSee (University of Texas, Houston), and compartmental modeling with the two-tissue model $^{5}$ implemented in syngoMBF (Siemens Healthineers). The authors' aims were to validate the retention

\footnotetext{
Edward P. Ficaro and Venkatesh L. Murthy equal contribution as cosenior authors

Reprint requests: Jonathan B. Moody, PhD, INVIA Medical Imaging Solutions, 3025 Boardwalk Street, Suite 200, Ann Arbor, MI 40108; jmoody@inviasolutions.com

J Nucl Cardiol 2020;27:829-32.

$1071-3581 / \$ 34.00$

Copyright (C) 2019 American Society of Nuclear Cardiology.
}

model for ${ }^{13} \mathrm{~N}$-ammonia cardiac PET/CT with the compartmental modeling serving as a reference standard, and to establish normal MBF reference values using the shorter retention model PET protocol.

The HeartSee software used in this study was developed at Dr K.L. Gould's lab at the University of Texas, which may be considered the reference implementation of the simplified retention model. ${ }^{8,14}$ The retention model has also been implemented in other academic and commercial software packages, including FlowQuant (Ottawa Heart), ImagenQ (CVIT), MunichHeart (Technical University of Munich), and 4DM (INVIA). Since the 1990s, several research groups have performed detailed validation studies of the retention model for both ${ }^{13} \mathrm{~N}$-ammonia ${ }^{6-8}$ and ${ }^{82} \mathrm{Rb}^{8,20}$ The major advantage of the retention model for clinical measurement of MBF is the simplified PET protocol and greatly reduced computing demands for image reconstruction and processing compared with compartmental modeling. The retention model trades flexibility for simplicity and efficiency, which, for earlier generations of clinical PET scanners, addressed the inherent technological limitations that made dynamic PET and full compartmental modeling impractical for routine use. ${ }^{8,21}$ Another important potential advantage of the retention model is reduced variability of the MBF estimates ${ }^{22,23}$ at the expense of increased bias due to the use of approximations and fixed correction factors. ${ }^{8}$ In routine clinical applications, utility is very often determined by physiological and methodological variability rather than systematic error (bias).

There are three primary limitations of the retention model. First, the model assumes that tracer taken up by the myocardium is irreversibly trapped and does not subsequently wash out. ${ }^{8}$ This approximation is 
sufficiently accurate for normally perfused, viable myocytes, but in practice, tracer washout may occur in the presence of severe ischemia or non-transmural scar. ${ }^{8,24}$ Our own recent work has demonstrated that ${ }^{82} \mathrm{Rb}$ washout can in fact be used to reliably assess myocardial viability in ischemic cardiomyopathy patients. ${ }^{25}$

Second, the retention model assumes that the entire integrated arterial input function can be captured during the initial fixed two-minute blood pool image, which may be inaccurate in cases with low cardiac function, or when physiological delay of the initial tracer bolus is exacerbated by the lack of a saline flush in the infusion system. ${ }^{26}$ A hybrid approach ${ }^{27}$ which largely overcomes this limitation (when list-mode acquisition is available on the PET scanner) consists in performing preliminary image reconstructions of short dynamic frames during the blood pool phase to determine the time course of activity in the left ventricle, and them summing the appropriate dynamic images to generate the integrated arterial input image. Although this procedure undermines the simplicity of the retention model, it can largely be automated, and additionally provides the opportunity to perform motion correction between dynamic frames during this crucial period of the PET acquisition. ${ }^{28}$

Finally, the retention model requires partial volumecorrection factors which must generally be determined locally by phantom scans for each PET scanner and radionuclide. ${ }^{8}$ Previous determinations have been described for ${ }^{82} \mathrm{Rb}$ and ${ }^{13} \mathrm{~N}$-ammonia for the University of Texas cesium-fluoride PET scanner, ${ }^{8}$ and for ${ }^{82} \mathrm{Rb}$ and ${ }^{18} \mathrm{~F}$ for the BGO-based GE Discovery ST PET/CT scanner. ${ }^{29}$ In the present study, ${ }^{19}$ although the manufacturer was noted (GE Healthcare), the PET scanner model was not reported, and the authors did not report the determination of partial volume-correction factors appropriate for their PET scanner or for ${ }^{13} \mathrm{~N}$-ammonia, although partial volume corrections were performed by the HeartSee software. ${ }^{19}$ It is common that the same fixed partial volume-correction factors are used for all patients, assuming a mean diastolic wall thickness of 1 $\mathrm{cm}$, which may become inaccurate at the extremes of very thin or very thick myocardial walls. This could be improved by utilizing patient-specific correction factors, ${ }^{29}$ but again this may reduce the simplicity and appeal of the retention model.

Does the retention model continue to offer advantages today? The retention model was primarily developed and utilized on 2D PET scanners, ${ }^{6,7,14,20}$ and may still be preferred or necessary in the case of older BGO-based PET-only and PET/CT scanners without list-mode capabilities. Some remanufactured 2D systems have now added list-mode features, and for such systems, the retention model with modifications mentioned above may offer some advantages over full compartmental modeling. However, all contemporary 3D PET/CT scanners have list-mode capabilities, and newer tracer delivery systems and clinical software have largely mitigated the technical challenges that previously limited the role of routine compartmental modeling and MBF estimation in the clinic.

Finally, did Chang et al ${ }^{19}$ achieve their stated aims in this study? The mean flows are consistent with values from the literature (see Ref. ${ }^{30}$ online appendix). However, it is necessary to consider the methodological variability of each approach to determine whether the MBF estimates from the two models are "close enough." The short-term repeatability (within minutes) of the retention model (in terms of the $95 \%$ repeatability coefficient, RPC) has only been reported for Rb-82 (15$20 \%),{ }^{22,23}$ while the $95 \%$ RPC of compartmental modeling is $20 \%$ for ${ }^{13} \mathrm{~N}$-ammonia. ${ }^{31}$ Considering the global flow estimates in Figure 1 of Ref. ${ }^{19}$, and using 95\% RPC limits of $\pm 20 \%$, we find that $27 \%$ of rest scans and $32 \%$ of stress scans were beyond these limits (Figure 1), suggesting a notable lack of agreement in as many as one-third of patients studied. Possible reasons for this disagreement might be the possible use of incorrect partial volume-correction factors in the retention model, or that metabolite correction was performed for the retention model but not for the compartmental model, which could lead to MBF underestimation by $5-10 \% .^{5,32}$ Moreover, regarding clinical efficiency, it is noteworthy that validation ${ }^{5,33}$ of the compartmental model used by Chang et $\mathrm{al}^{19}$ was originally demonstrated with PET

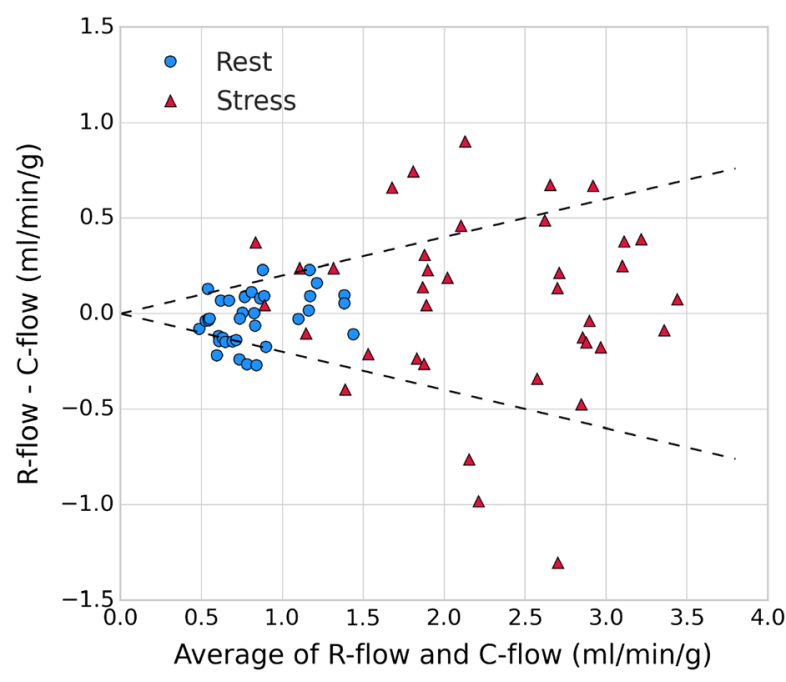

Figure 1. Bland-Altman global left ventricular flow data from Figure $1 \mathrm{~b}$ of reference, ${ }^{19}$ replotted with $95 \%$ repeatability limits (RPC $\pm 20 \%$, dashed lines). ${ }^{22,23,31} R$-flow Simplified retention model, $C$-flow compartment model. $27 \%$ of rest scans and $32 \%$ of stress scans were outside the $95 \%$ repeatability limits. 
scan durations of only $10 \mathrm{~min}$ (rather than the $16 \mathrm{~min}$ used here), and there are other validated compartmental models available for ${ }^{13} \mathrm{~N}$-ammonia that require even shorter durations. ${ }^{12,13}$

If the underlying goal is local implementation of reliable, routine clinical MBF measurement, Chang et al may be on the right track, but we must conclude that additional protocol optimization may be necessary. The difficulty is not a lack of tools, but a lack of technical standardization. The implementation process could be made truly simpler if all stakeholders engaged collaboratively to develop technical standards for $\mathrm{MBF}$ quantification that will ultimately bring quantifiable clinical value and tangible benefits for patient care.

\section{Disclosure}

J.B. Moody is an employee of INVIA. E.P. Ficaro is a stockholder of INVIA, which produces 4DM, a clinical software package for cardiac PET analysis. V.L. Murthy owns stock in General Electric and Cardinal Health and stock options in Ionetix. He has received consulting fees from Ionetix and Jubilant DraxImage. He has received grant funding from Siemens Medical Imaging. He has further received funding under \#Grant R01HL136685 from the National Heart, Lung, and Blood Institute; and Grant \#R01AG059729 from the National Institute on Aging.

\section{References}

1. Parker JA, Beller GA, Hoop B, Holman BL, Smith TW. Assessment of regional myocardial blood flow and regional fractional oxygen extraction in dogs, using ${ }^{15} \mathrm{O}$-water and ${ }^{15} \mathrm{O}$-hemoglobin. Circ Res. 1978;42:511-8.

2. Schelbert HR, Phelps ME, Hoffman EJ, Huang S-C, Selin CE, Kuhl DE. Regional myocardial perfusion assessed with N-13 labeled ammonia and positron emission computerized axial tomography. Am J Cardiol. 1979;43:209-18.

3. Budinger TF, Yano Y, Huesman RH, Sobel BE. Positron emission tomography of the heart. Physiologist. 1983;26:31-4.

4. Bergmann SR, Herrero P, Markham J, Weinheimer CJ, Walsh MN. Noninvasive quantitation of myocardial blood flow in human subjects with oxygen-15-labeled water and positron emission tomography. J Am Coll Cardiol. 1989;14:639-52.

5. Hutchins G, Schwaiger M, Rosenspire K, Krivokapich J, Schelbert $\mathrm{H}$, Kuhl D. Noninvasive quantification of regional blood flow in the human heart using N-13 ammonia and dynamic positron emission tomographic imaging. J Am Coll Cardiol. 1990;15:103242.

6. Bellina CR, Parodi O, Camici P, Salvadori PA, Taddei L, Fusani $\mathrm{L}$, et al. Simultaneous in vitro and in vivo validation of nitrogen13-ammonia for the assessment of regional myocardial blood flow. J Nucl Med. 1990;31:1335-43.

7. Nienaber CA, Ratib O, Gambhir SS, Krivokapich J, Huang SC, Phelps ME, et al. A quantitative index of regional blood flow in canine myocardium derived noninvasively with N-13 ammonia and dynamic positron emission tomography. J Am Coll Cardiol. 1991;17:260-9.
8. Yoshida K, Mullani N, Gould KL. Coronary flow and flow reserve by PET simplified for clinical applications using rubidium-82 or nitrogen-13-ammonia. J Nucl Med. 1996;37:1701-12.

9. Lortie M, Beanlands RSB, Yoshinaga K, Klein R, Dasilva JN, DeKemp RA. Quantification of myocardial blood flow with ${ }^{82} \mathrm{Rb}$ dynamic PET imaging. Eur $J$ Nucl Med Mol Imaging. 2007;34:1765-74.

10. Prior JO, Allenbach G, Valenta I, Kosinski M, Burger C, Delaloye $\mathrm{FR}$, et al. Quantification of myocardial blood flow with ${ }^{82} \mathrm{Rb}$ positron emission tomography: Clinical validation with ${ }^{15} \mathrm{O}$-water. Eur J Nucl Med Mol Imaging. 2012;39:1037-47.

11. Choi Y, Huang S-C, Hawkins RA, Kuhle WG, Dahlbom M, Hoh $\mathrm{CK}$, et al. A simplified method for quantification of myocardial blood flow using nitrogen-13-ammonia and dynamic PET. J Nucl Med. 1993;34:488-97.

12. DeGrado T, Hanson M, Turkington T, Delong DM, Brezinski DA, Vallée JP, et al. Estimation of myocardial blood flow for longitudinal studies with ${ }^{13} \mathrm{~N}$-labeled ammonia and positron emission tomography. J Nucl Cardiol. 1996;3:494-507.

13. Choi Y, Huang S-C, Hawkins RA, Kim JY, Kim BT, Hoh CK, et al. Quantification of myocardial blood flow using ${ }^{13} \mathrm{~N}$-ammonia and PET: Comparison of tracer models. J Nucl Med. 1999;40:1045-55.

14. Johnson NP, Gould KL. Physiological basis for angina and STsegment change: PET-verified thresholds of quantitative stress myocardial perfusion and coronary flow reserve. JACC Cardiovasc Imaging. 2011;4:990-8.

15. Slomka PJ, Alexanderson E, Jácome R, Jiménez M, Romero E, Meave A, et al. Comparison of clinical tools for measurements of regional stress and rest myocardial blood flow assessed with ${ }^{13} \mathrm{~N}$ ammonia PET/CT. J Nucl Med. 2012;53:171-81.

16. deKemp RA, Declerck J, Klein R, Nakazato R, Tonge C, Arumugam $\mathrm{P}$, et al. Multisoftware reproducibility study of stress and rest myocardial blood flow assessed with 3D dynamic PET/CT and a 1-tissue-compartment model of ${ }^{82} \mathrm{Rb}$ kinetics. J Nucl Med. 2013;54(4):571-7.

17. Nesterov SV, Deshayes E, Sciagrà R, Settimo L, Declerck JM, Pan $\mathrm{XB}$, et al. Quantification of myocardial blood flow in absolute terms using ${ }^{82} \mathrm{Rb}$ PET imaging: Results of RUBY-10 study. JACC Cardiovasc Imaging. 2014;7:1119-27.

18. Harms HJ, Nesterov SV, Han C, Danad I, Leonora R, Raijmakers $\mathrm{PG}$, et al. Comparison of clinical non-commercial tools for automated quantification of myocardial blood flow using oxygen-15labelled water PET/CT. Eur Heart J Cardiovasc Imaging. 2014;15:431-41.

19. Chang C-Y, Hung G-U, Hsu B, Yang BH, Chang CW, Hu LH, et al. Simplified quantification of ${ }^{13} \mathrm{~N}$-ammonia PET myocardial blood flow: A comparative study with the standard compartment model to facilitate clinical use. J Nucl Cardiol 2018;in press.

20. Lautamäki R, George R, Kitagawa K, Higuchi T, Merrill J, Voicu $\mathrm{C}$, et al. Rubidium-82 PET-CT for quantitative assessment of myocardial blood flow: Validation in a canine model of coronary artery stenosis. Eur J Nucl Med Mol Imaging. 2009;36:576-86.

21. Muzik O, Duvernoy C, Beanlands R, Sawada S, Dayanikli F, Wolfe ER, et al. Assessment of diagnostic performance of quantitative flow measurements in normal subjects and patients with angiographically documented coronary artery disease by means of nitrogen-13 ammonia and positron emission tomography. J Am Coll Cardiol. 1998;31:534-40.

22. Kitkungvan D, Johnson NP, Roby AE, Patel MB, Kirkeeide R, Gould KL. Routine clinical quantitative rest stress myocardial perfusion for managing coronary artery disease: Clinical relevance of test-retest variability. JACC Cardiovasc Imaging. 2016;10:56577. 
23. Klein R, Ocneanu A, Renaud JM, Ziadi MC, Beanlands RSB, deKemp RA. Consistent tracer administration profile improves test-retest repeatability of myocardial blood flow quantification with ${ }^{82} \mathrm{Rb}$ dynamic PET imaging. J Nucl Cardiol. 2016;25: 929-41.

24. Gould KL, Yoshida K, Hess MJ, Haynie M, Mullani N, Smalling RW. Myocardial metabolism of fluorodeoxyglucose compared to cell membrane integrity for the potassium analogue rubidium-82 for assessing infarct size in man by PET. J Nucl Med. 1991;32:19.

25. Moody JB, Hiller KM, Lee BC, et al. The utility of ${ }^{82} \mathrm{Rb}$ PET for myocardial viability assessment: Comparison with perfusionmetabolism ${ }^{82} \mathrm{Rb}^{18}{ }^{18}$-FDG PET. J Nucl Cardiol 2018;in press.

26. Renaud JM, Wu KY, Gardner K, Aung M, Beanlands RSB deKemp RA. Saline-push improves rubidium-82 PET image quality. J Nucl Cardiol. 2018. https://doi.org/10.1007/s12350-0181261-4.

27. Renaud JM, DaSilva JN, Beanlands RSB, deKemp RA. Characterizing the normal range of myocardial blood flow with ${ }^{82}$ rubidium and ${ }^{13} \mathrm{~N}$-ammonia PET imaging. J Nucl Cardiol. 2013;20:578-91.

28. Lee $\mathrm{BC}$, Moody JB, Poitrasson-Rivière A, Melvin AC, Weinberg RL, Corbett JR, et al. Blood pool and tissue phase patient motion effects on ${ }^{82}$ rubidium PET myocardial blood flow quantification. J Nucl Cardiol. 2018. https://doi.org/10.1007/s12350-018-1256-1.

29. Johnson NP, Sdringola S, Gould KL. Partial volume correction incorporating $\mathrm{Rb}-82$ positron range for quantitative myocardial perfusion PET based on systolic-diastolic activity ratios and phantom measurements. J Nucl Cardiol. 2011;18:247-58.

30. Gould KL, Johnson NP, Bateman TM, Beanlands RS, Bengel FM, Bober R, et al. Anatomic versus physiologic assessment of coronary artery disease Role of coronary flow reserve, fractional flow reserve, and positron emission tomography imaging in revascularization decision-making. J Am Coll Cardiol. 2013;62:1639-53.

31. Nagamachi S, Czernin J, Kim AS, Sun KT, Bottcher M, Phelps $\mathrm{ME}$, et al. Reproducibility of measurements of regional resting and hyperemic myocardial blood flow assessed with PET. J Nucl Med. 1996;37:1626-31.

32. Bormans G, Maes A, Langendries W, Nuyts J, Vrolix M, Vanhaecke J, et al. Metabolism of nitrogen-13 labelled ammonia in different conditions in dogs, human volunteers and transplant patients. Eur J Nucl Med Mol Imaging. 1995;22:116-21.

33. Muzik O, Beanlands RSB, Hutchins GD, Mangner TJ, Nguyen N, Schwaiger M. Validation of nitrogen-13-ammonia tracer kinetic model for quantification of myocardial blood flow using PET. J Nucl Med. 1993;34:83-91. 